\title{
Erratum: search-related suppression of hippocampus and default network activity during associative memory retrieval
}

\author{
Emilie T. Reas' ${ }^{1}$, Sarah I. Gimbel' ${ }^{1}$, Jena B. Hales ${ }^{1}$ and James B. Brewer 1,2* \\ 1 Department of Neurosciences, University of California, San Diego, La Jolla, CA, USA \\ ${ }^{2}$ Department of Radiology, University of California, San Diego, La Jolla, CA, USA \\ *Correspondence: jbrewer@ucsd.edu
}

Edited by:

Josef Parvizi, Stanford University Medical Center, USA

\section{A commentary on}

Search-related suppression of hippocampus and default network activity during associative memory retrieval

by Reas, E. T., Gimbel, S. I., Hales, J. B., and Brewer, J. B. (2011). Front. Hum. Neurosci. 5:112. doi: 10.3389/fnhum.2011.00112

Recent work using an analysis technique employed in this study has led us to realize that a section of our results should be restated. The following revised paragraph should replace the originally published paragraph on page 7 of our article, under the heading "Activity Correlations with Response Time."

\section{ACTIVITY CORRELATIONS WITH RESPONSE TIME}

To examine a possible relationship between response fluency and hippocampal and default network suppression, correlations between BOLD signal and response time were computed. Activity was negatively correlated with response time $(p<0.05)$ during both the classify and the recall tasks in bilateral superior temporal cortex and PCC. During only the recall, but not the classify task, negative correlations with response time were additionally observed in bilateral anterior hippocampus, medial PFC, and inferior parietal cortex. Thus, greater activity in these regions was correlated with a faster response time.

Received: 04 January 2013; accepted: 05 January 2013; published online: 24 January 2013.

Citation: Reas ET, Gimbel SI, Hales JB and Brewer JB (2013) Erratum: search-related suppression of hippocampus and default network activity during associative memory retrieval. Front. Hum. Neurosci. 7:2. doi: 10.3389/fnhum.2013. 00002

Copyright (c) 2013 Reas, Gimbel, Hales and Brewer. This is an open-access article distributed under the terms of the Creative Commons Attribution License, which permits use, distribution and reproduction in other forums, provided the original authors and source are credited and subject to any copyright notices concerning any third-party graphics etc. 